\title{
Fetal Programming of Adrenal Androgen Excess: Lessons from a Nonhuman Primate Model of Polycystic Ovary Syndrome
}

\author{
David H. Abbott ${ }^{\mathrm{a}-\mathrm{c}} \cdot$ Rao Zhou ${ }^{\mathrm{a}}$ lan M. Birda,c . \\ Daniel A. Dumesic ${ }^{\mathrm{b}, \mathrm{d}} \cdot$ Alan J. Conley \\ aDepartment of Obstetrics and Gynecology, bWisconsin National Primate Research Center \\ and 'Endocrinology-Reproductive Physiology Training Program, University of Wisconsin, \\ Madison, Wisc., 'Reproductive Medicine and Infertility Associates, Woodbury, Minn., and \\ ePopulation Health and Reproduction, School of Veterinary Medicine, \\ University of California-Davis, Davis, Calif., USA
}

\begin{abstract}
Adrenal androgen excess is found in adult female rhesus monkeys previously exposed to androgen treatment during early gestation. In adulthood, such prenatally androgenized female monkeys exhibit elevated basal circulating levels of dehydroepiandrosterone sulfate (DHEAS), typical of polycystic ovary syndrome (PCOS) women with adrenal androgen excess. Further androgen and glucocorticoid abnormalities in PA female monkeys are revealed by acute ACTH stimulation: DHEA, androstenedione and corticosterone responses are all elevated compared to responses in controls. Pioglitazone treatment, however, diminishes circulating DHEAS responses to ACTH in both prenatally androgenized and control female monkeys, while increasing the 17-hydroxyprogesterone response and reducing the DHEA to 17-hydroxyprogesterone ratio. Since 60-min post-ACTH serum values for 17-hydroxyprogesterone correlate negatively with basal serum insulin levels (all female monkeys on pioglitazone and placebo treatment combined), while similar DHEAS values correlate positively with basal serum insulin levels, circulating insulin levels may preferentially support adrenal androgen biosynthesis in both prenatally androgenized and control female rhesus monkeys. Overall, our findings suggest that differentiation of the monkey adrenal cortex in a hyperandrogenic fetal environment may permanently upregulate adult adrenal androgen biosynthesis through specific elevation of 17,20-lyase activity in the zona fasciculata-reticularis. As adult prenatally androgenized female rhesus monkeys closely emulate PCOS-like symptoms, excess fetal androgen programming may contribute to adult adrenal androgen excess in women with PCOS.

Copyright $\odot 2008$ S. Karger AG, Basel
\end{abstract}

In contrast to many mammals, the primate adrenal cortex is well endowed with androgen biosynthetic machinery located within two developmentally specific adrenocortical zones: the fetal zone and the zona reticularis $[1,2]$. While the androgen-producing fetal 
zone develops during gestation and regresses shortly after birth, the androgenic zona reticularis, the innermost cortical zone, develops later in life and functionally matures at adrenarche [3-5]. Both adrenocortical zones produce the adrenal androgen dehydroepiandrosterone (DHEA) and its sulfoconjugate DHEAS, while androstenedione is produced in relatively small amounts due to the reduced expression of $3 \beta$-hydroxysteroid dehydrogenase II (3 $\beta$-HSD II) [2].

The androgenic predilection of the zona reticularis stems from the preferential conversion of 17-hydroxypregnenolone to DHEA (with onward sulfoconjugation to DHEAS), rather than to 17-hydroxyprogesterone (and onward conversion to cortisol), because of (1) diminished expression of $3 \beta-H S D$ II, together with relatively high expression of (2) the androgenic biosynthetic enzyme P450c17 (17 $\alpha$-hydroxylase/ 17,20-lyase), (3) the catalytic accessory protein, cytochrome b5, required for efficient 17,20-lyase activity, and (4) an obligate electron donor for P450c17 activity, NADPH cytochrome P450 oxidoreductase [1,2] (fig. 1). Implicit in this steroidogenic activity is the fact that primates, in contrast to rodents, derive most of their androgen biosynthesis via the $\Delta 5$ steroidogenic pathway (fig. 1) because 17-hydroxyprogesterone, as an inefficient substrate for primate 17,20-lyase, is negligibly converted to androstenedione $[1,2]$.

Old World monkeys [i.e., rhesus macaques (Macaca mulatta) from the Indian subcontinent], great apes and humans exhibit analogous maturation of the androgenic adrenal zona reticularis [6], with all undergoing adrenarche, or increased adrenal DHEA and DHEAS secretion [2] coincident with greatly reduced expression of $3 \beta$ HSD II within the zona reticularis. Monkeys differ from great apes and humans, however, with respect to the developmental timing of adrenarche. In contrast to progressive differentiation of the zona reticularis from neonatal to adolescent stages in great apes and humans $[2,7]$, such progressive maturation of the zona reticularis in rhesus monkeys and baboons occurs during late fetal to neonatal life coincident with regression of the fetal zone $[2,5]$. Rhesus monkeys, therefore, have close similarities to adrenal androgen physiology found in humans making them appropriate animal models for investigating pathophysiological mechanisms underlying adrenal androgen excess.

This chapter focuses on a potential fetal programming etiology for adrenal androgen excess in polycystic ovary syndrome (PCOS), a hyperandrogenic, infertility and metabolic disorder found in 6-7\% of reproductive-aged women [8-10]. PCOS accounts for $82 \%$ of women presenting with androgen excess [11] and between 20 and $30 \%$ of PCOS women exhibit adrenal androgen excess, manifest by elevated circulating levels of DHEA, DHEAS and androstenedione [12-15], as well as specific DHEA and androstenedione hyperandrogenic responses to ACTH [16]. Moreover, DHEAS levels are generally elevated in most women with PCOS, suggesting a prevalent adrenal contribution to this hyperandrogenic condition because of the unique adrenal origins of the conjugated steroid [14]. While hyperandrogenic adrenal responses to ACTH in PCOS women are not necessarily accompanied by other 


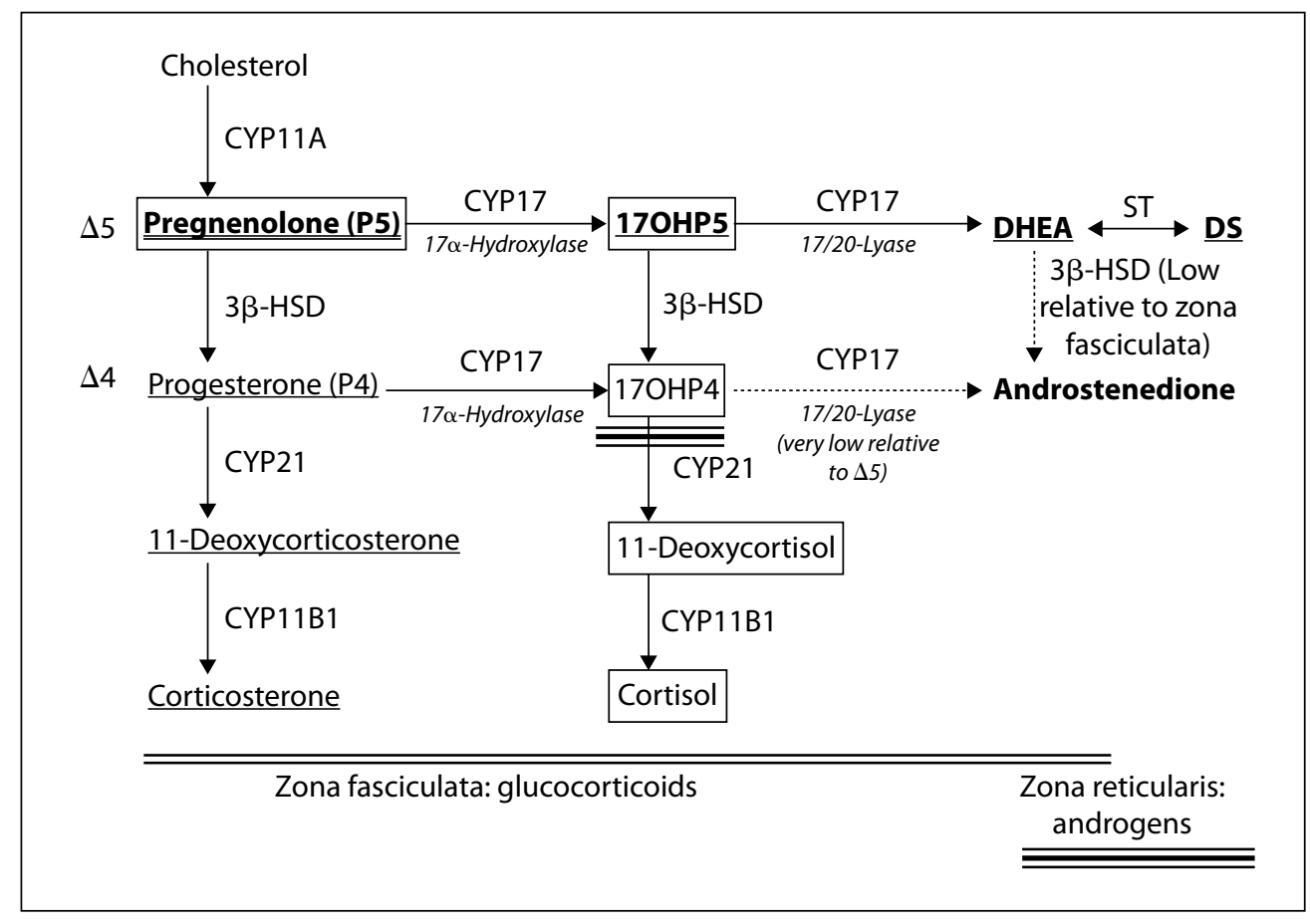

Fig. 1. Steroid biosynthesis in the mid to inner adrenal cortical zones, zona fasciculata and zona reticularis, of Old World primates and humans. Steroids in bold represent the predominant pathway for androgen biosynthesis, steroids within boxes represent the predominant pathway for cortisol biosynthesis, and underlined steroids represent the predominant pathway for corticosterone biosynthesis. The long arrows reflect the proposed enhanced 3 $\beta$-HSD II and 17,20-lyase enzymatic function in PA female monkeys, while the dotted arrows reflect relative low enzymatic activity in both control and PA females. Double underlining reflects the extent of zona fasciculata enzymatic activity, while triple underlining reflects the extent of zona reticularis enzymatic activity. $170 \mathrm{HP} 5=17 \alpha$-Hydroxypregnenolone; $170 H P 4=17 \alpha$-hydroxyprogesterone; CYP11A = P450scc; CYP17 = P450c17; ST = SULT2A1 sulfotransferase; $D S=$ dehydroepiandrosterone sulfate; $C Y P 21=$ P450c21; CYP11B1 = P450c11 [modified from 31].

remarkable adrenal abnormalities of the zona glomerulosa and zona fasciculata, or the hypothalamic-pituitary-adrenal axis [16, 17], some PCOS studies suggest a generalized hypersecretion of adrenal steroids [15], or ACTH hyperresponsiveness to corticotropin-releasing hormone (CRH) $[18,19]$. The latter, however, may reflect diminished somatostatin release in PCOS women [20], particularly since somatostatin treatment reduces $\mathrm{CRH}$-mediated ACTH release in PCOS women [21].

To explore a fetal programming origin for adrenal androgen excess in PCOS, adrenal androgen abnormalities were examined in adult female rhesus monkeys exposed in utero to androgen excess. These prenatally androgenized female rhesus monkeys closely mimic the reproductive, infertility and metabolic phenotypes found in PCOS women [22] and show a similar degree of adrenal androgen excess. 


\section{Prenatally Androgenized Female Rhesus Monkeys as Models of Adrenal Androgen Excess}

Prenatally androgenized female rhesus monkeys are generated by exposure to fetal male levels of testosterone during early or late gestation. Their pregnant mothers receive subcutaneous injections of $10-15 \mathrm{mg}$ testosterone propionate for up to 41 consecutive days, starting on gestation days 40-44 (early) or 100/110 (late) in approximately 165-day term pregnancies [23]. Such experimentally induced androgen excess generates PCOS-like phenotypes when prenatally androgenized females reach adulthood [22]. Early gestation-exposed prenatally androgenized female monkeys show irregular or absent ovulatory menstrual cycles, ovarian hyperandrogenism, enlarged polyfollicular ovaries and luteinizing hormone hypersecretion, in addition to insulin resistance, diminished insulin secretion, increased incidence of type 2 diabetes, visceral adiposity and hyperlipidemia [22, 24-27]. Female monkeys similarly exposed to androgen excess during late gestation also exhibit an adult PCOS-like phenotype, but without obvious abnormalities in luteinizing hormone and insulin secretion or in insulin action [22].

Both types of adult prenatally androgenized monkeys demonstrate ovarian androgen excess. For example, $24 \mathrm{~h}$ after an intramuscular injection of $200 \mathrm{IU}$ of recombinant human chorionic gonadotropin, both early and late gestation-exposed prenatally androgenized female monkey groups exhibit elevated circulating testosterone levels compared to controls [22]. Early gestation-exposed prenatally androgenized monkeys also show an elevated ovarian 17-hydroxyprogesterone response to recombinant human chorionic gonadotropin [28] together with elevated basal testosterone levels $[27,29]$. These females with more obvious signs of fetal programming of adult hyperandrogenism were thus studied to determine whether they had adrenal androgen excess comparable to that found in PCOS women.

\section{Potential Adrenal Hyperandrogenism in Infant Prenatally Androgenized Monkeys Exposed to Fetal Androgen Excess during Early Gestation}

In rhesus monkeys, early infancy coincides not only with regression of the androgenproducing fetal zone of the adrenal, but also with the simultaneous maturation of the androgenic zona reticularis $[2,5]$. From at least birth to 1 month of age, prenatally androgenized female monkeys exhibit elevated circulating levels of androstenedione [23], indicative of adrenal and/or ovarian androgen excess. Our preliminary findings suggest that adrenal androgen excess does contribute to this hyperandrogenism in infant prenatally androgenized females, given the elevated protein expression of adrenal P450 oxidoreductase and possibly cytochrome b5 [Conley and Abbott, unpubl. results]. Interestingly, infant male rhesus monkeys exhibit an adrenal-dependent rise 
in circulating testosterone levels between 4 and 25 weeks of age [30] so that exposure to fetal androgen excess (fetal male or prenatally androgenized female) during early gestation may permanently enhance adrenal androgen biosynthesis following birth.

\section{Adrenal Hyperandrogenism in Adult Prenatally Androgenized Monkeys Exposed to Fetal Androgen Excess during Early Gestation}

As a sign of functional adrenal hyperandrogenism, prenatally androgenized female monkeys exposed to androgen excess during early gestation exhibit elevated basal circulating levels of DHEA [31] and DHEAS [28]. Elevated basal DHEAS levels are a primary indicator of adrenal androgen excess in women with PCOS [15, 32, 33] suggesting that prenatally androgenized monkeys may closely emulate their PCOS human counterparts in this adrenal abnormality. To examine prenatally androgenized monkey adrenal steroid dysfunction in more detail, we utilize acute ACTH stimulation (at $07: 30$ to $08: 00 \mathrm{~h}$ ) administered $14.5-16 \mathrm{~h}$ after dexamethasone treatment (Dex-ACTH) on days 2-6 of the menstrual cycle or during a 30-day anovulatory interval. We employ a high intravenous dose of ACTH $(50 \mu \mathrm{g} ; \sim 5.5 \mu \mathrm{g} / \mathrm{kg}$ of human $\mathrm{ACTH}_{1-39}$ ) to saturate the preferred $\mathrm{P} 450 \mathrm{c} 17 \Delta 5$ pathway and to reveal any minor shifts in steroidogenesis from 17-hydroxypregnenolone to progesterone via increased 3 $\beta$-HSD II activity [31] (fig. 1). Such ACTH-mediated adrenocortical stimulation further illustrates the functional adrenal hyperandrogenism of prenatally androgenized female monkeys, with elevated serum DHEA and androstenedione responses to ACTH (fig. 2) [31] accompanied by normal serum 17-hydroxyprogesterone and cortisol responses to ACTH. Note that the latter result suggests an additional, but normal, zona reticularis origin of circulating 17-hydroxyprogesterone, since P450c21 in the zona fasciculata would rapidly metabolize this product to deoxycortisol (fig. 1).

In these prenatally androgenized female monkeys, the relatively greater increase in serum DHEA compared to serum 17-hydroxyprogesterone, androstenedione and DHEAS in response to Dex-ACTH causes (1) an increased ratio of serum DHEA to 17-hydroxyprogesterone and (2) diminished ratios of serum DHEAS to DHEA, and serum androstenedione to DHEA [31]. Such adrenal androgen excess in early gestation-exposed prenatally androgenized female monkeys corresponds with selectively increased 17,20-lyase activity in the zona fasciculata (elevated DHEA and androstenedione levels) as well as in the zona reticularis (elevated DHEA levels). This enhanced efficiency of 17,20-lyase activity in the prenatally androgenized monkey adrenal, however, occurs without enhanced $17 \alpha$-hydroxylase activity, since basal and ACTH-induced levels of 17-hydroxyprogesterone (from the zona reticularis) and cortisol (from the zona fasciculata) are normal. A putative molecular basis for an isolated lyase activity increase in prenatally androgenized monkey adrenals could be increased serine phosphorylation of $\mathrm{P} 450 \mathrm{c} 17$ [31] possibly facilitated by an increase of cytochrome 


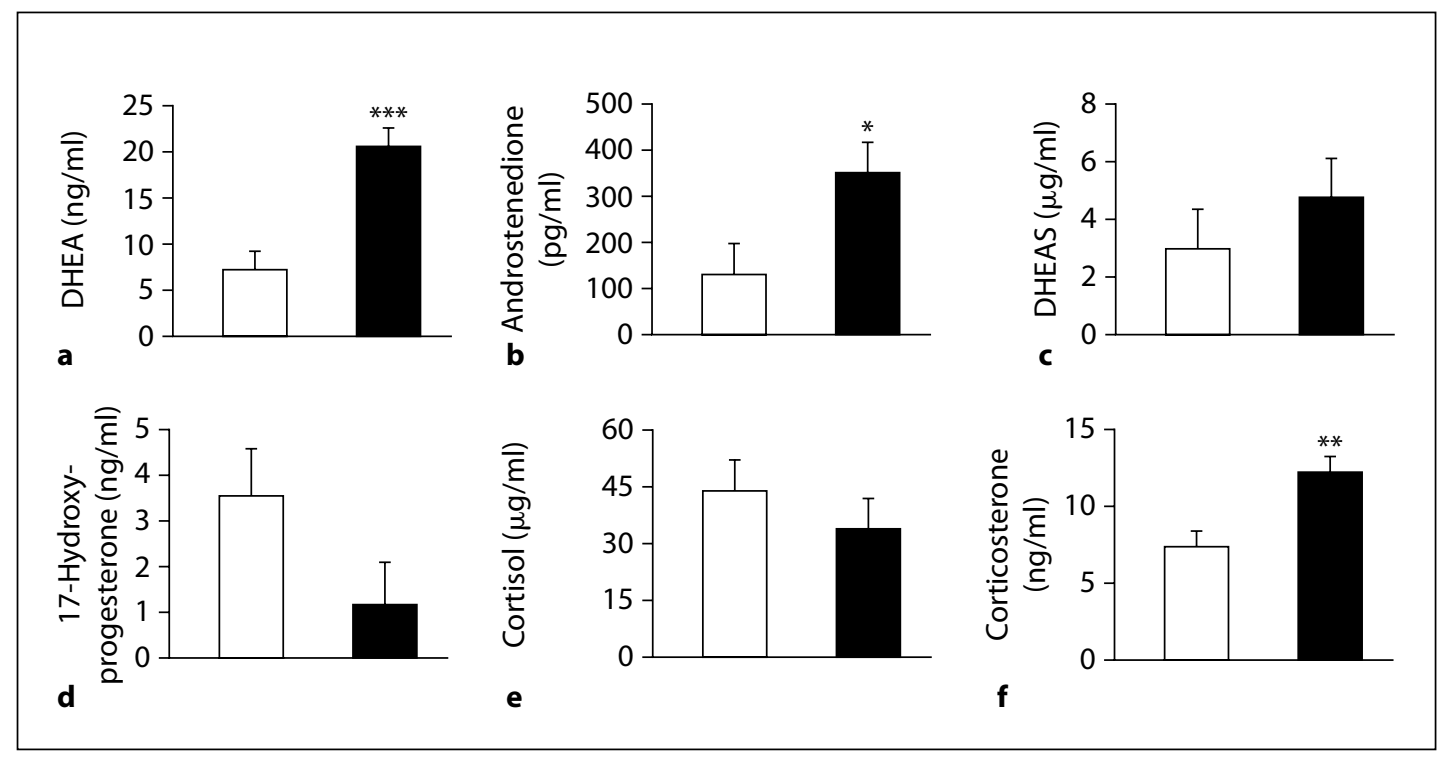

Fig. 2. The differential in circulating adrenal steroid values between 0 and $60 \mathrm{~min}$ following an intravenous injection of $50 \mu \mathrm{g} \mathrm{ACTH}$ in adult control $(\square)$ and prenatally androgenized ( $\mathbf{\square})$ female rhesus monkeys for adrenal androgen-related steroids: DHEA (a), androstenedione (b) and DHEAS (c), as well as adrenal glucocortoicoid-related steroids: 17-hydroxyprogesterone (d), cortisol (e) and corticosterone (f) [modified from 31]. ${ }^{*} p>0.05 ;{ }^{* *} p>0.03 ;{ }^{* * *} p>0.01$.

b5 or P450 oxidoreductase, or most likely in view of the involvement of insulin sensitivity, a combination of all three. Additionally, conversion of excessive DHEA to DHEAS via SULT2A1 sulfotransferase in the zona reticularis, and to androstenedione via $3 \beta-H S D$ II in the zona fasciculata (and to a greatly reduced extent in the zona reticularis; fig. 1), could provide one explanation for the elevated levels of these latter two androgenic adrenal steroids in the absence of an altered cortisol response.

To account for the increased corticosterone response to ACTH combined with adrenal hyperandrogenism in prenatally androgenized female monkeys, however, additional enzymatic changes in adrenal steroid biosynthesis and metabolism must exist beyond enhanced 17,20-lyase in the zona fasciculata and zona reticularis. While pregnenolone is the preferred substrate for cortisol biosynthesis in primates, a small amount of progesterone byproduct is the basis for corticosterone biosynthesis by the zona fasciculata (fig. 1) $[2,6,34,35]$. The corticosterone response is produced primarily in the primate zona fasciculata $[2,6]$, and is elevated following ACTH stimulation in prenatally androgenized females, so we must assume $3 \beta-\mathrm{HSD}$ II activity is elevated in the zona fasciculata of these monkeys. This hypothesis agrees with a 3-4\% decrease in the efficiency of cortisol biosynthesis in the zona fasciculata (derived from the increased ratio of corticosterone to cortisol at $60 \mathrm{~min}$ after ACTH administration) 
Table 1. Differences in mean \pm SEM circulating adrenal steroid values between 0 and 60 min following an intravenous injection of $50 \mu \mathrm{g} \mathrm{ACTH}$ in the combined group of control and prenatally androgenized female rhesus monkeys receiving placebo or pioglitazone treatment [27]

\begin{tabular}{lccl}
\hline Steroid & 0- to 60-min placebo & $\begin{array}{c}\text { 0- to 60-min } \\
\text { pioglitazone }\end{array}$ & p value \\
\hline $17 \alpha$-Hydroxyprogesterone, $\mathrm{ng} / \mathrm{ml}$ & $2.3 \pm 1.0$ & $3.6 \pm 1.0$ & $\mathrm{NS}$ \\
Cortisol, $\mu \mathrm{g} / \mathrm{dl}$ & $34.9 \pm 3.8$ & $36.7 \pm 3.9$ & $\mathrm{NS}$ \\
DHEA, $\mathrm{ng} / \mathrm{ml}$ & $16.7 \pm 1.7$ & $17.9 \pm 1.8$ & $\mathrm{NS}{ }^{1}$ \\
DHEAS, $\mu \mathrm{g} / \mathrm{dl}$ & $6.9 \pm 1.5$ & $2.2 \pm 1.6$ & $<0.05$ \\
Androstenedione, $\mathrm{pg} / \mathrm{ml}$ & $213 \pm 52$ & $345 \pm 78$ & $\mathrm{NS}$ \\
Corticosterone, $\mathrm{ng} / \mathrm{ml}$ & $11.1 \pm 1.2$ & $10.8 \pm 1.1$ & $\mathrm{NS}$ \\
\hline
\end{tabular}

$\mathrm{NS}=\mathrm{p}>0.05$

${ }^{1}$ The difference in serum DHEA levels between 0 and 60 min post-ACTH injection for prenatally androgenized female monkeys exceeds that in control females, regardless of placebo or pioglitazone treatment (treatment values combined: prenatally androgenized, $20.0 \pm 1.8 \mathrm{ng} / \mathrm{ml}$; controls, $14.5 \pm 1.8 \mathrm{ng} / \mathrm{ml} ; \mathrm{p}<0.05)$.

[34] of prenatally androgenized female monkeys, as well as an $\sim 14$-fold increase in corticosterone versus an $\sim 8$-fold increase in cortisol following ACTH administration [31]. While enhanced $3 \beta$-HSD II activity exists in some PCOS women with adrenal androgen excess [36], it is unclear whether this phenomenon translates into corticosterone hyperresponsiveness to ACTH in humans.

\section{Insulin Is Associated with Adrenal Androgen Excess in Prenatally Androgenized Female Monkeys}

As in PCOS [37], insulin is associated with the pathophysiological mechanism of reproductive and endocrine abnormalities in prenatally androgenized female rhesus monkeys, as evidenced by a 6-month study of pioglitazone treatment, a thiazolidinedionebased insulin sensitizer. Pioglitazone treatment not only diminishes insulin resistance and reduces circulating insulin levels, but also normalizes menstrual cyclicity and diminishes ovarian hyperandrogenism in most prenatally androgenized female monkeys [27], similar to its effects in PCOS women [38, 39].

Similar to its effects in PCOS women [40, 41], pioglitazone treatment of prenatally androgenized female monkeys diminishes aspects of adrenal androgen excess. Serum DHEAS responses to ACTH are reduced in both prenatally androgenized and control female monkeys (table 1), analogous to findings of reduced basal serum DHEAS levels in PCOS women undergoing treatment with troglitazone [42]. In prenatally 
androgenized female monkeys alone, pioglitazone normalizes $(\mathrm{p}<0.02)$ the serum DHEA to 17-hydroxyprogesterone ratio at $60 \mathrm{~min}$ following ACTH administration (prenatally androgenized, placebo: $22.0 \mathrm{ng} / \mathrm{ml}$ (16.9, 28.7), pioglitazone: 8.1 (6.1, 10.8); control, placebo: 7.3 (1.9, 28.8), pioglitazone: $7.7(2.0,26.7)$ (backtransformed logarithmic mean; 95\% confidence interval). Serum DHEA responses to ACTH, however, remain elevated at their previously reported values (compare table 1 to fig. 2) in prenatally androgenized compared to control female monkeys regardless of whether they receive pioglitazone or placebo treatment.

Together, these pioglitazone-mediated changes in adrenal steroidogenesis predominantly implicate a specific reduction in 17,20-lyase activity following the pioglitazone-mediated decline in circulating insulin levels. Such a notion is consistent with the negative correlation between 60 -min post-ACTH 17-hydroxyprogesterone levels and basal insulin (fig. 3a), the positive correlation between 60 -min post-ACTH DHEAS levels and basal insulin (fig. 3b) and the overall negative correlation between 0-min pre-ACTH 17-hydroxyprogesterone and DHEAS levels (fig. 3c) in all female monkeys combined. Decreased serine phosphorylation of P450c17 [33, 43], decreased cytochrome b5 activity $[43,44]$, decreased concentrations of the electrondonating redox partner for 17,20-lyase, P450 oxidoreductase $[45,46]$, or a combination of all three may provide a molecular basis for the relatively diminished 17,20-lyase activity observed in pioglitazone-treated prenatally androgenized female monkeys. It is unlikely that such diminished adrenal androgen excess is a direct result of pioglitazone action. Pioglitazone, at therapeutic doses, increases P450 oxidoreductase expression $[47,48]$, increases melanocortin $2(\mathrm{ACTH})$ receptor expression and cortisol responses to ACTH [49], and downregulates expression of P450c17 and $3 \beta$-HSD II [50].

The finding of pioglitazone-mediated decrease in 17,20-lyase activity agrees with compensatory hyperinsulinemia from insulin resistance playing a causal role in adrenal hyperandrogenism in PCOS $[51,52]$, and with insulin-enhanced adrenal androgen responses to ACTH in PCOS [53]. Moreover, if enhanced 17,20-lyase activity extends into the adrenal zona fasciculata, it can also contribute to proportionately increased DHEA biosynthesis, perhaps even at the expense of $17 \alpha$-hydroxyprogesterone and cortisol production, as found in the highly inbred Angora goat [54]. Such an expansive function for 17,20-lyase in the zona fasciculata might also contribute towards the lack of concomitant increase in $17 \alpha$-hydroxyprogesterone and cortisol (fig. 1) following ACTH in prenatally androgenized versus control female monkeys.

Insulin stimulation of $\mathrm{P} 450 \mathrm{c} 17$ in the adrenal cortex of PCOS women, if similar to its action in theca cells from polycystic ovaries, acts through the PI3-kinase branch of the insulin signaling pathway, to synergize with additional coactivation by cAMP/kinase A [55]. Such insulin overstimulation of P450c17 under circumstances of insulin resistance at the level of glucose metabolism would suggest that steroidogenesis and glucose metabolism are regulated by alternate signaling events distal to 


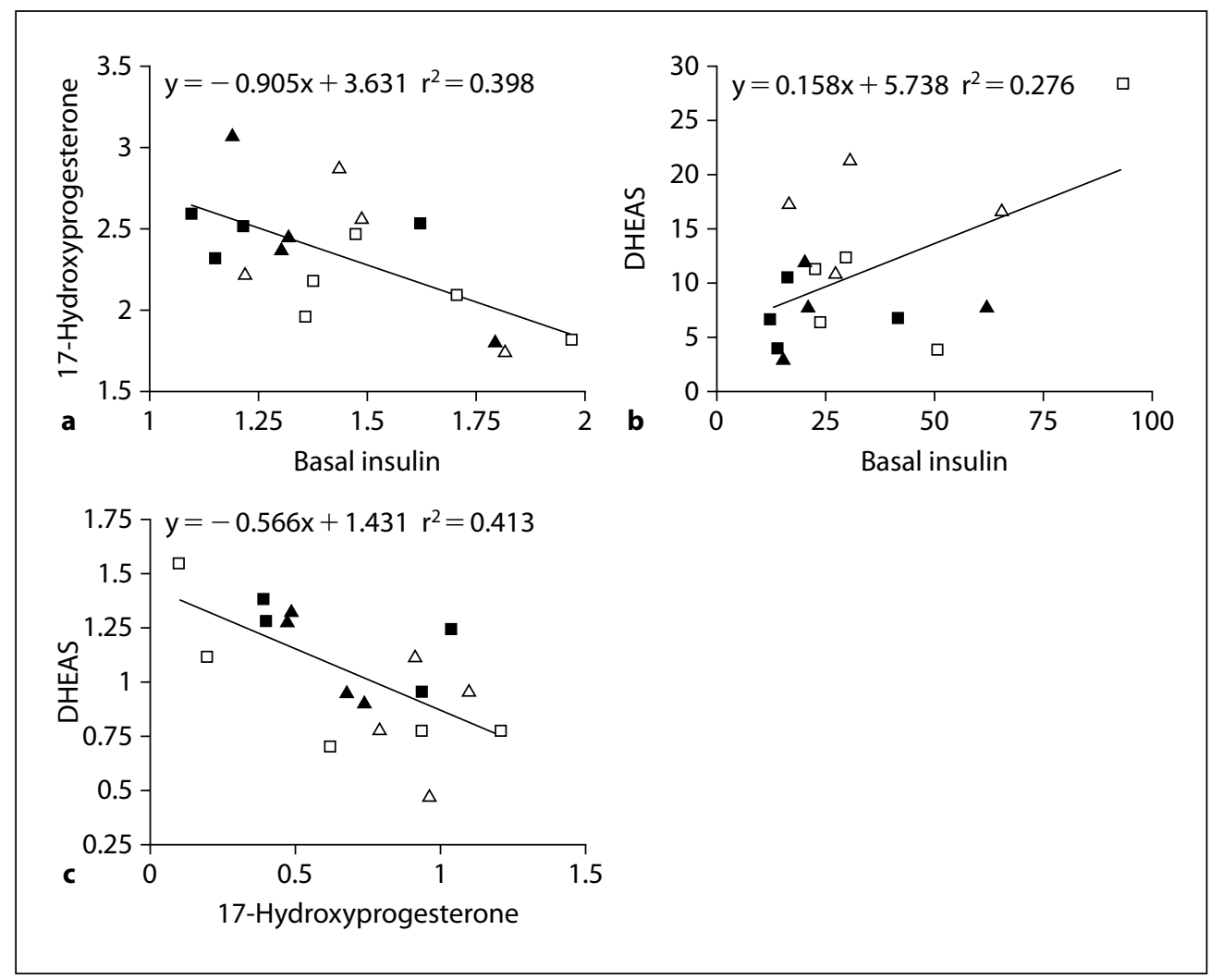

Fig. 3. Associations $(p<0.05)$ between serum values of 17 -hydroxyprogesterone at $60 \mathrm{~min}$ following an intravenous injection of $50 \mu \mathrm{g} \mathrm{ACTH}$ and basal insulin (a), DHEAS at $60 \mathrm{~min}$ following an intravenous injection of $50 \mu \mathrm{g} \mathrm{ACTH}$ and basal insulin (b), and DHEAS and 17-hydroxyprogesterone at 0 min following an intravenous injection of $50 \mu \mathrm{g} \mathrm{ACTH} \mathrm{(c)} \mathrm{in} \mathrm{control} \mathrm{(} \triangle=$ placebo treatment [27]; $\boldsymbol{\Delta}=$ pioglitazone treatment [27]) and PA ( $\square=$ placebo; $\mathbf{\square}=$ pioglitazone) female monkeys. Data are expressed as $\log _{10}$-transformed serum values only in a and $\mathbf{c}$. Units used: 17-hydroxyprogesterone, $\log _{10} \mathrm{ng} / \mathrm{ml}$; insulin, $\log _{10} \mu \mathrm{U} / \mathrm{ml}$ (a); DHEAS, $\mu \mathrm{g} / \mathrm{dll}$; insulin, $\mu \mathrm{U} / \mathrm{ml}(\mathbf{b})$, and DHEAS, $\log _{10} \mu \mathrm{g} / \mathrm{dl} ; 17-$ hydroxyprogesterone, $\log _{10} \mathrm{ng} / \mathrm{ml}(\mathbf{c})$.

PI3-kinase activation [55], and would explain the absence of insulin resistance in terms of steroidogenic enzyme regulation in the ovary [56] as well as the adrenal.

\section{Potential Fetal Programming Origins of Adrenal Androgen Excess}

In the adrenal cortex, androgens are implicated in the regulation of their own biosynthesis. For example, adrenocortical cells express androgen receptors [57, 58], flutamide (an androgen receptor antagonist) diminishes adrenal androgen biosynthesis in PCOS women $[59,60]$, while testosterone can directly affect adrenal androgen 
biosynthesis [61]. Taken together, a hyperandrogenic environment during fetal life may influence adrenal cortical differentiation in a manner that enhances fetal zone androgen biosynthesis.

Alternatively, insulin appears to upregulate androgen biosynthesis in the adrenal cortex of normal [61] and PCOS women [53], and in the polycystic ovary [36]. Since both fetal [29] and infant [62] prenatally androgenized female rhesus monkeys exhibit enhanced insulin secretion, the fetal zone and infant zona reticularis may be susceptible to increased insulin-mediated serine phosphorylation of P450c17, thus preferentially enhancing 17,20-lyase activity by increasing the affinity of P450c17 for its electron donor, P450 oxidoreductase [33,43]. Therefore, fetal androgen excess may induce relative insulin hypersecretion in exposed female fetuses and infants, which in turn programs adrenal hyperandrogenism.

\section{Conclusions and Therapeutic Considerations}

Androgen excess, during early to midgestation in female rhesus monkeys, causes a remarkably close phenocopy of adrenal hyperandrogenism found in $20-30 \%$ of PCOS women. The ability to experimentally induce adrenal androgenism by fetal programming further suggests that specific changes in adrenal gene expression, perhaps from epigenetic alterations of gene methylation [63,64], may contribute to adrenal androgen excess beyond genotypic determination [65]. While the molecular mechanisms underlying adrenal pathophysiology in PCOS women and prenatally androgenized female monkeys are incompletely understood, isolated enhancement of adrenocortical 17,20-lyase activity appears to be a common attribute, as evidenced by the elevated expression of $\mathrm{P} 450$ oxidoreductase, and possibly cytochrome b5, found in the adrenal cortex of our prenatally androgenized female monkeys [Conley and Abbott, unpubl. results]. It remains to be determined whether such molecular underpinnings of adrenal androgen excess are induced by the direct actions of testosterone, its androgenic or estrogenic metabolites, or by the hyperandrogenic induction of fetal and infant insulin hypersecretion. Regardless, our findings of fetal programming of adrenal androgen excess in a nonhuman primate model for PCOS suggest that such hyperandrogenism may be a consequence of fetal environmental influences rather than a primary, intrinsic defect.

Therapeutic use of low-dose flutamide reliably diminishes adrenal androgen excess in PCOS women [66]. Unfortunately, the use of flutamide to investigate possible direct effects of androgen excess in the fetal female environment on adrenal androgen biosynthesis is difficult due to its permanent effects on somatosensory and cognitive function in rhesus monkeys exposed during fetal development [67, 68]. On the other hand, insulin sensitizers alone (PCOS women [40, 41]; prenatally androgenized monkeys [27]) or in combination with flutamide [69], also ameliorate adrenal androgen excess in both PCOS women and adult female prenatally androgenized 
monkeys, without inducing hepatoxicity. Therefore, nonteratogenic insulin sensitizers such as metformin [70], in addition to their potential benefits in reducing pregnancy complications in PCOS [71], may prove useful in exploring how androgen-induced fetal hyperinsulinism programs adrenal hyperandrogenism. Future studies are required to determine whether insulin sensitizer treatment of pregnant PCOS women or pregnant testosterone propionate-treated monkeys will prevent postnatal adrenal hyperandrogenism and other phenotypic characteristics of PCOS in their daughters and confirm a specific programming mechanism.

\section{Acknowledgments}

This work was supported by NIH grants R01 RR013635, P50 HD044405, U01 HD044650 and P51 RR000167. This research was conducted at a facility constructed with support from Research Facilities Improvement Program grant No. RR15459 and RR020141.

\section{References}

$>1$ Conley AJ, Bird IM: The role of cytochrome P450 17 alpha-hydroxylase and 3 beta-hydroxysteroid dehydrogenase in the integration of gonadal and adrenal steroidogenesis via the delta 5 and delta 4 pathways of steroidogenesis in mammals. Biol Reprod 1997; 56:789-799.

2 Conley AJ, Pattison JC, Bird IM: Variations in adrenal androgen production among (nonhuman) primates. Semin Reprod Med 2004;22:311-326.

-3 Mesiano S, Jaffe RB: Developmental and functional biology of the primate fetal adrenal cortex. Endocr Rev 1997;18:378-403.

4 Mapes S, Tarantal AF, Parker CR, Moran FM, Bahr JM, Pyter L, Conley AJ: Adrenocortical cytochrome b5 expression during fetal development of the rhesus macaque. Endocrinology 2002;143:1451-1458.

5 Nguyen AD, Conley AJ: Adrenal androgens in humans and nonhuman primates: Production, zonation and regulation; in Flueck CE, Miller WL (eds): Disorders of the Human Adrenal Cortex. Basel, Karger, 2008, pp 33-54.

6 Arlt W, Martens JW, Song M, Wang JT, Auchus RJ, Miller WL: Molecular evolution of adrenarche: structural and functional analysis of $\mathrm{P} 450 \mathrm{c} 17$ from four primate species. Endocrinology 2002;143:4665-4672.

7 Sklar CA, Kaplan SL, Grumbach MM: Evidence for dissociation between adrenarche and gonadarche: studies in patients with idiopathic precocious puberty, gonadal dysgenesis, isolated gonadotropin deficiency, and constitutionally delayed growth and adolescence. J Clin Endocrinol Metab 1980;51:548-556.
Diamanti-Kandarakis E, Kouli CR, Bergiele AT, Filandra FA, Tsianateli TC, Spina GG, Zapanti ED, Bartzis MI: A survey of the polycystic ovary syndrome in the Greek island of Lesbos: hormonal and metabolic profile. J Clin Endocrinol Metab 1999;84: 4006-4011.

-9 Asuncion M, Calvo RM, San Millan JL, Sancho J, Avila S, Escobar-Morreale HF: A prospective study of the prevalence of the polycystic ovary syndrome in unselected Caucasian women from Spain. J Clin Endocrinol Metab 2000;85:2434-2438.

10 Azziz R, Woods KS, Reyna R, Key TJ, Knochenhauer ES, Yildiz BO: The prevalence and features of the polycystic ovary syndrome in an unselected population. J Clin Endocrinol Metab 2004;89:2745-2749.

11 Azziz R, Sanchez LA, Knochenhauer ES, Moran C, Lazenby J, Stephens KC, Taylor K, Boots LR: Androgen excess in women: experience with over 1000 consecutive patients. J Clin Endocrinol Metab 2004; 89:453-462.

12 Wild RA, Umstot ES, Andersen RN, Ranney GB, Givens JR: Androgen parameters and their correlation with body weight in one hundred thirty-eight women thought to have hyperandrogenism. Am J Obstet Gynecol 1983;146:602-606.

13 Carmina E, Koyama T, Chang L, Stanczyk FZ, Lobo RA: Does ethnicity influence the prevalence of adrenal hyperandrogenism and insulin resistance in polycystic ovary syndrome? Am J Obstet Gynecol 1992;167:1807-1812. 
14 Kumar A, Woods KS, Bartolucci AA, Azziz R: Prevalence of adrenal androgen excess in patients with the polycystic ovary syndrome (PCOS). Clin Endocrinol (Oxf) 2005;62:644-649.

15 Yildiz BO, Azziz R: The adrenal and polycystic ovary syndrome. Rev Endocr Metab Disord 2007;8: 331-342.

16 Azziz R, Black V, Hines GA, Fox LM, Boots LR: Adrenal androgen excess in the polycystic ovary syndrome: sensitivity and responsivity of the hypothalamic-pituitary-adrenal axis. J Clin Endocrinol Metab 1998;83:2317-2323.

17 Pasquali R, Patton L, Pocognoli P, Cognigni GE, Gambineri A: 17-Hydroxyprogesterone responses to gonadotropin-releasing hormone disclose distinct phenotypes of functional ovarian hyperandrogenism and polycystic ovary syndrome. J Clin Endocrinol Metab 2007;92:4208-4217.

18 Kondoh Y, Uemura T, Ishikawa M, Yokoi N, Hirahara F: Classification of polycystic ovary syndrome into three types according to response to human corticotropin-releasing hormone. Fertil Steril 1999;72: 15-20.

19 Lanzone A, Petraglia F, Fulghesu AM, Ciampelli M, Caruso A, Mancuso S: Corticotropin-releasing hormone induces an exaggerated response of adrenocorticotropic hormone and cortisol in polycystic ovary syndrome. Fertil Steril 1995;63:1195-1199.

20 Wu XK, Wang CH, Su YH: Responses of somatostatin, beta-endorphin and dynorphin A to a glucose load in two groups of women with polycystic ovarian syndrome. Horm Res 1996;46:59-63.

21 Lanzone A, Fulghesu AM, Guido M, Cucinelli F, Caruso A, Mancuso S: Somatostatin treatment reduces the exaggerated response of adrenocorticotropin hormone and cortisol to corticotropinreleasing hormone in polycystic ovary syndrome. Fertil Steril 1997;67:34-39.

22 Abbott DH, Barnett DK, Bruns CM, Dumesic DA: Androgen excess fetal programming of female reproduction: a developmental aetiology for polycystic ovary syndrome? Hum Reprod Update 2005;11: 357-374.

23 Abbott DH, Barnett DK, Turk JM, Levine JE, Padmanabhan V, Dumesic DA, Jacoris S, Tarantal AF: Endocrine antecedents of polycystic ovary syndrome in fetal and infant prenatally androgenized female rhesus monkeys. Biol Reprod 2008; Apr 2; [Epub ahead of print].

24 Dumesic DA, Schramm RD, Abbott DH: Early origins of polycystic ovary syndrome. Reprod Fertil Dev 2005;17:349-360.
25 Eisner JR, Dumesic DA, Kemnitz JW, Abbott DH: Timing of prenatal androgen excess determines differential impairments in insulin secretion and action in adult female rhesus monkeys. J Clin Endocrinol Metab 2000;85:1206-1210.

26 Bruns CM, Baum ST, Colman RJ, Dumesic DA, Eisner JR, Jensen MD, Whigham LD, Abbott DH: Prenatal androgen excess negatively impacts body fat distribution in a nonhuman primate model of polycystic ovary syndrome. Int J Obes (Lond) 2007;31: 1579-1585.

27 Zhou R, Bruns CM, Bird IM, Kemnitz JW, Goodfriend TL, Dumesic DA, Abbott DH: Pioglitazone improves insulin action and normalizes menstrual cycles in a majority of prenatally androgenized female rhesus monkeys. Reprod Toxicol 2007;23: 438-448.

28 Eisner JR, Barnett MA, Dumesic DA, Abbott DH: Ovarian hyperandrogenism in adult female rhesus monkeys exposed to prenatal androgen excess. Fertil Steril 2002;77:167-172.

29 Abbott DH, Barnett DK, Bruns CM, Dunaif A, Dumesic DA: Transient hyperglycemia in both mother and fetus from experimental induction of maternal androgen excess in a nonhuman primate model for polycystic ovary syndrome (abstract P3113). 88th Annual Meeting of the Endocrine Society, Boston, 2006.

30 Plant TM, Zorub DS: A study of the role of the adrenal glands in the initiation of the hiatus in gonadotropin secretion during prepubertal development in the male rhesus monkey (Macaca mulatta). Endocrinology 1984;114:560-565.

31 Zhou R, Bird IM, Dumesic DA, Abbott DH: Adrenal hyperandrogenism is induced by fetal androgen excess in a rhesus monkey model of polycystic ovary syndrome. J Clin Endocrinol Metab 2005; 90:6630-6637.

32 Carmina E, Lobo RA: Prevalence and metabolic characteristics of adrenal androgen excess in hyperandrogenic women with different phenotypes. J Endocrinol Invest 2007;30:111-116.

33 Zhang LH, Rodriguez H, Ohno S, Miller WL: Serine phosphorylation of human P450c17 increases 17, 20-lyase activity: implications for adrenarche and the polycystic ovary syndrome. Proc Natl Acad Sci USA 1995;92:10619-10623.

34 Pattison JC, Abbott DH, Saltzman W, Mapes SM, Moran FM, Corbin CJ, Nguyen AD, Pryce CR, Allen AJ, Conley AJ, Bird IM: Male marmoset monkeys express an adrenal fetal zone at birth but not a zona reticularis in adulthood. Endocrinology 2005; 146:365-374. 
35 Pattison JC, Saltzman W, Abbott DH, Hogan BK, Nguyen AD, Husen B, Einspanier A, Conley AJ, Bird IM: Gender and gonadal status differences in zona reticularis expression in marmoset monkey adrenals: cytochrome b5 localization with respect to cytochrome P450 17,20-lyase activity. Mol Cell Endocrinol 2007;265-266:93-101.

36 Doi SA, Al-Zaid M, Towers PA, Scott CJ, Al-Shoumer KA: Steroidogenic alterations and adrenal androgen excess in PCOS. Steroids 2006;71:751-759.

37 Dunaif A: Insulin resistance and the polycystic ovary syndrome: mechanism and implications for pathogenesis. Endocr Rev 1997;18:774-800.

38 Brettenthaler N, De Geyter C, Huber PR, Keller U: Effect of the insulin sensitizer pioglitazone on insulin resistance, hyperandrogenism, and ovulatory dysfunction in women with polycystic ovary syndrome. J Clin Endocrinol Metab 2004;89:3835-3840.

\$39 Romualdi D, Guido M, Ciampelli M, Giuliani M, Leoni F, Perri C, Lanzone A: Selective effects of pioglitazone on insulin and androgen abnormalities in normo- and hyperinsulinaemic obese patients with polycystic ovary syndrome. Hum Reprod 2003; 18:1210-1218.

40 Guido M, Romualdi D, Suriano R, Giuliani M, Costantini B, Apa R, Lanzone A: Effect of pioglitazone treatment on the adrenal androgen response to corticotrophin in obese patients with polycystic ovary syndrome. Hum Reprod 2004;19:534-539.

41 Romualdi D, Giuliani M, Draisci G, Costantini B, Cristello F, Lanzone A, Guido M: Pioglitazone reduces the adrenal androgen response to corticotropinreleasing factor without changes in ACTH release in hyperinsulinemic women with polycystic ovary syndrome. Fertil Steril 2007;88:131-138.

42 Azziz R, Ehrmann DA, Legro RS, Fereshetian AG, O'Keefe M, Ghazzi MN, PCOS/Troglitazone Study Group: Troglitazone decreases adrenal androgen levels in women with polycystic ovary syndrome. Fertil Steril 2003;79:932-937.

43 Pandey AV, Miller WL: Regulation of 17,20 lyase activity by cytochrome $\mathrm{b} 5$ and by serine phosphorylation of P450c17. J Biol Chem 2005;280:13265-13271.

44 Auchus RJ, Lee TC, Miller WL: Cytochrome b5 augments the 17,20-lyase activity of human P450c17 without direct electron transfer. J Biol Chem 1998; 273:3158-3165.

45 Yanagibashi K, Hall PF: Role of electron transport in the regulation of the lyase activity of $\mathrm{C} 21$ side-chain cleavage P-450 from porcine adrenal and testicular microsomes. J Biol Chem 1986;261:8429-8433.

46 Lin D, Black SM, Nagahama Y, Miller WL: Steroid 17 alpha-hydroxylase and 17,20-lyase activities of P450c17: contributions of serine106 and P450 reductase. Endocrinology 1993;132:2498-2506.
47 Prough RA, Webb SJ, Wu HQ, Lapenson DP, Waxman DJ: Induction of microsomal and peroxisomal enzymes by dehydroepiandrosterone and its reduced metabolite in rats. Cancer Res 1994;54: 2878-2886.

48 Waxman DJ: Role of metabolism in the activation of dehydroepiandrosterone as a peroxisome proliferator. J Endocrinol 1996;150(suppl):S129-S147.

49 Betz MJ, Shapiro I, Fassnacht M, Hahner S, Reincke M, Beuschlein F, German and Austrian Adrenal Network: Peroxisome proliferator-activated receptor-gamma agonists suppress adrenocortical tumor cell proliferation and induce differentiation. J Clin Endocrinol Metab 2005;90:3886-3896.

50 Kempná P, Hofer G, Mullis PE, Flück CE: Pioglitazone inhibits androgen production in NCI-H295R cells by regulating gene expression of CYP17 and HSD3B2. Mol Pharmacol 2007;71:787-798.

1 Lanzone A, Fulghesu AM, Guido M, Fortini A, Caruso A, Mancuso S: Differential androgen response to adrenocorticotropic hormone stimulation in polycystic ovarian syndrome: relationship with insulin secretion. Fertil Steril 1992;58:296-301.

52 Arslanian SA, Lewy V, Danadian K, Saad R: Metformin therapy in obese adolescents with polycystic ovary syndrome and impaired glucose tolerance: amelioration of exaggerated adrenal response to adrenocorticotropin with reduction of insulinemia/ insulin resistance. J Clin Endocrinol Metab 2002;87: 1555-1559.

53 Moghetti P, Castello R, Negri C, Tosi F, Spiazzi GG, Brun E, Balducci R, Toscano V, Muggeo M: Insulin infusion amplifies 17 alpha-hydroxycorticosteroid intermediates response to adrenocorticotropin in hyperandrogenic women: apparent relative impairment of 17,20-lyase activity. J Clin Endocrinol Metab 1996;81:881-886.

54 Storbeck KH, Swart AC, Slabbert JT, Swart P: The identification of two CYP17 alleles in the South African Angora goat. Drug Metab Rev 2007;39: 467-480.

55 Munir I, Yen HW, Geller DH, Torbati D, Bierden RM, Weitsman SR, Agarwal SK, Magoffin DA: Insulin augmentation of 17alpha-hydroxylase activity is mediated by phosphatidyl inositol 3-kinase but not extracellular signal-regulated kinase-1/2 in human ovarian theca cells. Endocrinology 2004; 145:175-183.

6 Rice S, Christoforidis N, Gadd C, Nikolaou D, Seyani L, Donaldson A, Margara R, Hardy K, Franks S: Impaired insulin-dependent glucose metabolism in granulosa-lutein cells from anovulatory women with polycystic ovaries. Hum Reprod 2005;20:373-381. 
57 Stalvey JR: Inhibition of 3beta-hydroxysteroid dehydrogenase-isomerase in mouse adrenal cells: a direct effect of testosterone. Steroids 2002;67:721-731.

58 Pelletier G: Localization of androgen and estrogen receptors in rat and primate tissues. Histol Histopathol 2000;15:1261-1270.

59 Diamanti-Kandarakis E, Mitrakou A, Hennes MM, Platanissiotis D, Kaklas N, Spina J, Georgiadou E, Hoffmann RG, Kissebah AH, Raptis S: Insulin sensitivity and antiandrogenic therapy in women with polycystic ovary syndrome. Metabolism 1995;44: 525-531.

60 De Leo V, la Marca A, Lanzetta D, Cariello PL, D'Antona D, Morgante G: Effects of flutamide on pituitary and adrenal responsiveness to corticotrophin releasing factor (CRF). Clin Endocrinol (Oxf) 1998; 49:85-89.

61 Hines GA, Smith ER, Azziz R: Influence of insulin and testosterone on adrenocortical steroidogenesis in vitro: preliminary studies. Fertil Steril 2001;76: 730-735.

62 Abbott DH, Goodfriend TL, Dunaid A, Muller SJ, Dumesic DA, Tarantal AF: Increased body weight and enhanced insulin sensitivity in infant female rhesus monkeys exposed to androgen excess during early gestation (abstract P2-348). 89th Annual Meeting of the Endocrine Society, Toronto, 2007.

63 Liu J, Li XD, Vaheri A, Voutilainen R: DNA methylation affects cell proliferation, cortisol secretion and steroidogenic gene expression in human adrenocortical NCI-H295R cells. J Mol Endocrinol 2004;33: 651-662.
64 Weaver IC, Cervoni N, Champagne FA, D’Alessio AC, Sharma S, Seckl JR, Dymov S, Szyf M, Meaney MJ: Epigenetic programming by maternal behavior. Nat Neurosci 2004;7:847-854.

65 Goodarzi MO, Antoine HJ, Azziz R: Genes for enzymes regulating dehydroepiandrosterone sulfonation are associated with levels of dehydroepiandrosterone sulfate in polycystic ovary syndrome. J Clin Endocrinol Metab 2007;92:2659-2664.

66 Gambineri A, Pelusi C, Genghini S, Morselli-Labate AM, Cacclari M, Pagotto U, Pasquali R: Effect of flutamide and metformin administered alone or in combination in dieting obese women with polycystic ovary syndrome. Clin Endocrinol 2004;60:241.

67 McFadden D, Pasanen EG, Raper J, Lange HS, Wallen K: Sex differences in otoacoustic emissions measured in rhesus monkeys (Macaca mulatta). Horm Behav 2006;50:274-284.

68 Herman RA, Wallen K: Cognitive performance in rhesus monkeys varies by sex and prenatal androgen exposure. Horm Behav 2007;51:496-507.

69 Ibáñez L, López-Bermejo A, del Rio L, Enríquez G, Valls C, de Zegher F: Combined low-dose pioglitazone, flutamide, and metformin for women with androgen excess. J Clin Endocrinol Metab 2007;92: $1710-1714$.

70 Glueck CJ, Wang P: Metformin before and during pregnancy and lactation in polycystic ovary syndrome. Expert Opin Drug Saf 2007;6:191-198.

71 Salvesen KA, Vanky E, Carlsen SM: Metformin treatment in pregnant women with polycystic ovary syndrome - is reduced complication rate mediated by changes in the uteroplacental circulation? Ultrasound Obstet Gynecol 2007;29:433-437. 